\title{
Discurso político e o ethos coronelista em Esplanada, Bahia
}

\section{Elias Ramos da Silva}

Mestre em Estudo de Linguagens pela Universidade do Estado da Bahia (UNEB), Brasil. elias_uefs@yahoo.com.br

Resumo: Neste artigo, busca-se investigar a materialidade do ethos coronelista na fala do candidato eleito a prefeito de Esplanada (BA). O corpus é a entrevista concedida ao jornal local Esplanada News, realizada no ano de 2012. O aporte teórico advém da Análise do Discurso desenvolvida por Maingueneau e da Nova Retórica desenvolvida por Perelman e Olbrechts-Tyteca. Também é utilizado o conceito de "coronelismo" de Leal e o conceito de discurso político de Charaudeau. Para abordar o contexto sócio-histórico, dialoga-se com duas obras de Hildeth Cardoso de Faria, pois este autor nos apresenta dados sobre a memória da cidade, em que é possível identificar a presença da cultura do coronelismo. Após término da análise do corpus, verificou-se na fala do prefeito eleito a materialidade de um ethos e de um anti-ethos com algumas marcas da cultura do coronelismo.

Palavras-chave: Ethos. Argumentação. Discurso político. Coronelismo. Esplanada.

\begin{abstract}
This paper aims to research the construction of the ethos of the elected mayoral candidate to the city of Esplanada (BA). The corpus is the interview he gave to the local newspaper Esplanada News, during the electoral campaign in 2012. The theoretical framework is grounded on the French approach to Discourse Analysis developed by Maingueneau, on Perelman and Olbrechts-Tyteca approach to argumentation, on Leal's concept of coronelism and on Charaudeau's discussion on political discourse. In order to approach the socio- historical context, we draw on Faria's books. We concluded, through the analysis, that the construction of the elected mayor ethos and anti-ethos is marked by features of a coronelist culture.
\end{abstract}

Keywords: Ethos. Argumentation. Political Discourse. Coronelism. Esplanada. 
Introdução

Desde que cheguei à cidade de Esplanada em 2008, percebi que o tom dado ao discurso político não é o mesmo que se apresenta na cidade de Salvador - minha terra natal. Não que um seja melhor ou pior do que o outro. Mas, simplesmente, porque em cada cidade a práxis discursiva dá um corpo ao fiador, que, mesmo aparentando semelhanças entre si, apresentam sentidos diferentes.

De acordo com Charaudeau (2011), o discurso político como processo de influência social é complexo, uma vez que a política depende bastante da sua práxis e se inscreve constitutivamente nas relações de influência social; e a linguagem, por causa do fenômeno de circulação do discurso, é o que possibilita a criação de espaços de discussão, espaços de persuasão e de sedução nos quais são elaborados o pensamento e a ação política.

$\mathrm{Na}$ visão de Maingueneau (2011a), a concepção “encarnada” do ethos recobre não apenas a dimensão verbal, mas também o conjunto de determinações físicas e psíquicas ligados ao "fiador" através das representações coletivas estereotípicas. Dessa forma, atribui-se ao "fiador" uma "corporalidade" e um "caráter", cujos graus de precisão oscilam segundo os textos. Assim, o "caráter" equivale a um feixe de traços psicológicos. Referente à "corporalidade", pode-se dizer que ela está ligada a uma compleição física e a uma maneira de vestir-se. Logo, o ethos está vinculado a uma maneira de se deslocar no espaço social, uma disciplina tácita do corpo apreendida por meio de um comportamento.

Neste artigo, é apresentado um recorte da dissertação defendida na Universidade do Estado da Bahia (UNEB) pelo Programa de Pós-Graduação em Estudo de Linguagens (PPGEL), em 2017. Sendo assim, busca-se analisar a materialidade do ethos coronelista no discurso político a partir da fala do candidato eleito a prefeito do município de Esplanada (BA). O corpus é um excerto da entrevista concedida ao jornal local Esplanada News, durante o processo eleitoral de 2012, mais especificamente, a parte que trata da educação e da segurança.

O aporte teórico é alicerçado na Análise do Discurso de linha francesa desenvolvida por Maingueneau (2011). No entanto, são utilizadas a noção de discurso político de Charaudeau (2011) e a noção de argumentação de Perelman e Olbrechts-Tyteca (2005 [1958]). Para abordar o contexto sócio- 
histórico, dialoga-se com duas obras de Hildeth Cardoso de Faria - "História de Esplanada desde o início, no fim do século XIX" e "Oitenta anos de vida: reminiscência" -, pois elas nos apresentam dados sobre a memória da cidade.

Depois de analisar o corpus em questão, verificou-se que a fala do candidato eleito a prefeito materializa um ethos e um anti-ethos cujas marcas sinalizam a presença da cultura coronelista na cidade de Esplanada, Bahia.

\section{O discurso político em Charaudeau}

Segundo Charaudeau (2011), o termo "política" tem sido objeto de estudo das disciplinas Ciências da Linguagem, Ciências Políticas, Antropologia Social, Psicologia Social, Sociologia, Filosofia. Contudo, observa-se que nenhuma delas apresenta esse objeto como acabado.

Para tratar da noção de discurso político, Charaudeau (2011) afirma que um linguista do discurso sabe que os contextos psicológico e social determinam o sentido da linguagem. Por isso, em seus estudos, são integrados conceitos e categorias pertencentes a outras disciplinas humanas e sociais. Sendo assim, para construir e estudar seu objeto, cabe ao pesquisador elaborar a problemática geral a qual servirá de guia para sua análise. No caso da obra "Discurso Político", "trata-se de tomar uma posição quanto às relações entre linguagem, ação, poder e verdade, a fim de determinar a problemática particular na qual será estudado o discurso político" (CHARAUDEAU, 2011, p. 16). O presente trabalho também apresenta uma tomada de posição referente ao objeto de estudo em questão. Logo, não se tem a pretensão de dar a questão por encerrada; pelo contrário, visa-se suscitar novas pesquisas preocupadas com as relações de poder no interior do estado da Bahia.

Para este autor, a palavra 'política' está diretamente ligada à questão do poder. Por isso, defende a ideia de que a noção de campo político está associada a três termos: ação política, instância e valores. Na sua concepção,

[...] sem exagerar a complexidade das relações de força que se instauram nesse campo, parece que é possível determinar quando são tratadas simultaneamente, e em interação, as questões da ação política, de sua finalidade e de sua organização; as instâncias que são partes interessadas nessa ação; os valores em nome dos quais é realizada essa ação (CHARAUDEAU, 2011, p.16).

A citação acima deixa claro que o campo político é marcado por relações de força; não dá para pensá-lo desvinculado da questão do poder. Assim como 
não dá para pensar na consciência de si, sem pensar na existência do outro, pois é a partir da alteridade que o sujeito pode se definir. Na visão de Charaudeau (2011, p. 16), "os princípios de alteridade, de influência e de regulação são fundadores do ato de linguagem que o inscrevem em um quadro de ação, em uma praxiologia do agir sobre o outro". Dessa forma, as relações de força que constroem paralelamente o vínculo social estão vinculadas a todo ato de linguagem.

$\mathrm{Na}$ concepção do autor, a produção de sentidos é uma questão de interação, pois é segundo os modos de interação e a identidade dos participantes implicados que se constitui o pensamento político. Sendo assim, propõe distinguir três lugares de fabricação desse pensamento - um pode ser compreendido como o lugar de elaboração dos sistemas de pensamento, um como o lugar do qual o sentido está ligado ao próprio ato de comunicação, um como o lugar onde é produzido o comentário. Observemos a distinção de cada um desses lugares:

O discurso político como sistema de pensamento é o resultado de uma atividade discursiva que procura fundar um ideal político em função de certos princípios que devem servir de referência para a construção das opiniões e dos posicionamentos (CHARAUDEAU, 2011, p. 40).

O discurso político como ato de comunicação concerne mais diretamente aos atores que participam da cena de comunicação política, cujo desafio consiste em influenciar as opiniões a fim de obter adesões, rejeições ou consensos (CHARAUDEAU, 2011, p.40).

O discurso político como comentário não está necessariamente voltado para o fim político. O proposito é o conceito político, mas o discurso inscreve-se em uma situação cuja finalidade está fora do campo da ação política: é um discurso a respeito do político, sem risco político (CHARAUDEAU, 2011, p.40).

Essa divisão é interessante porque ela possibilita reconhecer que o discurso político se manifesta não apenas no 'intragoverno", mas também no 'extragoverno'2. Entretanto, há um ponto de convergência entre esses lugares - a linguagem alia-se à ação, reciprocamente. Por isso, comenta Arendt (1961, p. 235, apud CHARAUDEAU, 2011, p. 41-42),

[...] sem o acompanhamento da linguagem, a ação não perderia somente seu caráter revelador, ela perderia também, por assim, dizer, seu sujeito; não haveria

\footnotetext{
${ }^{1}$ Para o autor, o termo corresponde a um desafio de ação no qual a palavra política se faz performativa com o objetivo de governar com os parceiros diversos.

${ }^{2}$ De acordo com o autor, esse termo corresponde a um desafio de deliberação no qual a palavra circula entre os mesmos parceiros sem que estes tenham poder de decisão.
} 
homens, mas robôs executando atos que, humanamente falando, permaneceriam incompreensíveis. A ação muda não seria mais ação, pois não haveria mais ator e o ator, este fazedor de atos, não é possível se ele não for, ao mesmo tempo, falador de palavras. A ação que ele começa é revelada humanamente pelo verbo, e ainda que possamos perceber seu ato em sua aparência física bruta sem acompanhamento verbal, o ato não adquire um sentido senão pela palavra na qual o agente identifica-se como ator, anunciando o que ele faz, o que ele fez, o que ele quer fazer.

O fragmento supracitado ajuda a evidenciar um pouco melhor o campo de influência destes diferentes lugares de fabricação do discurso político, isto é, de que o discurso é o lugar de influência do outro, de engajamento do sujeito e de justificação de seu posicionamento.

\section{Argumentação e ethos em Maingueneau}

Para os estudiosos da retórica e da argumentação, o Tratado da Argumentação: a Nova Retórica rompe com uma concepção da razão e do raciocínio provenientes de Descartes.

De acordo com Perelman e Olbrechts-Tyteca (2005[1958]), o ponto mais importante que culminou com a ruptura do tratado da argumentação com a Retórica tradicional foi pensar a maneira como a Antiguidade lidava com a retórica e com a dialética.

Vale esclarecer que a dialética sempre tratou do verossímil. No entanto, percebe-se que Perelman e Olbrechts-Tyteca (2005[1958]) ampliam, em certos pontos, os limites da retórica antiga, na medida em que o objeto da retórica antiga era, sobretudo, a arte de falar em público de maneira persuasiva, ao passo que, no Tratado da Argumentação, o que se observa é uma preocupação com as questões acerca da estrutura da argumentação. Sendo assim, a obra não se limita ao exame da técnica do discurso oral, dando atenção, portanto, ao exame da escrita. O que é conservado da retórica tradicional é a noção de auditório ${ }^{3}$, a qual é imediatamente evocada assim que se pensa em um discurso.

No tratado da Argumentação, também se propõe que uma defesa de tese tem como ponto de partida o acordo. Uma vez que o acordo "tem por

\footnotetext{
${ }^{3}$ Na perspectiva de Perelman e Olbrechts-Tyteca (2005[1958], p. 22), auditório é “o conjunto daqueles que o orador quer influenciar com sua argumentação." Mas esse termo também pode ser "empregado, muita vezes, em concordância com o "ouvinte", no entanto ele designa um receptor de comunicação oral obrigatoriamente coletivo: o conjunto de participantes presentes em uma situação na qual o orador se dirige a um público - conferência, comício político, colóquio, mesa redonda etc.(CHARAUDEAU; MAINGUENEAU, 2012).
} 
objeto ora conteúdos das premissas explicitas, as ligações particulares utilizadas, ora a forma de servir-se dessas ligações; do princípio ao fim, a análise da argumentação versa sobre o que é presumidamente admitido pelo ouvinte" (PERELMAN E OLBRECHTS-TYTECA, 2005[1958], p. 75). Na argumentação, existem diferentes tipos de objetos de acordo. Alguns deles, como os fatos ${ }^{4}$, as verdades ${ }^{5}$ e as presunções ${ }^{6}$, beneficiam-se do acordo do auditório universal. Já os valores ${ }^{7}$, as hierarquias ${ }^{8}$ e os lugares ${ }^{9}$, beneficiam-se de auditórios particulares. Entretanto, é comum que, visando ao interesse de sua argumentação, o orador procure situar o debate no plano que lhe for mais favorável, alterando, caso jugue necessário, o estatuto de certos acordos.

Faz-se mister dizer que para Perelman e Olbrechts-Tyteca (2005), os argumentos quase-lógicos são aqueles que, por sua estrutura, lembram os raciocínios formais, dedutivos, todavia, diferentemente da linguagem formal, que é unívoca, eles são sujeitos a uma polissemia de sentidos, uma vez que empregam a linguagem natural, ou seja, ordinária. Para os autores supracitados, os argumentos quase-lógicos são mais bem compreendidos quando associados ao pensamento formal; já os argumentos baseados na estrutura do real são apresentados como análogos à própria estrutura das coisas, fundamentando-se em pontos de vista; e os argumentos que visam fundar a estrutura do real são aqueles que se apoiam no caso particular, como os argumentos por analogia, os quais se dedicam a reestruturar certos elementos do pensamento em consonância com esquemas outorgados em outros campos do real.

\footnotetext{
${ }^{4}$ Conforme os autores, a ideia de fato é qualificada pela noção que se tem de determinados acordos a respeitos de certos dados - aqueles que se referem a uma realidade objetiva e designariam, segundo Poincaré (1946, p. 65, apud Perelman e Olbrechts-Tyteca, 2005[1958], p.75), "o que é comum a vários entes e poderia ser comum a todos".

${ }^{5}$ Tudo que se compreende por fatos chama-se verdades, mas é preferível pensar a noção de verdade como um sistema mais complexo, relativo a ligações entre fatos, que trate de teorias científicas ou de ideias filosóficas que transcendem a experiência.

${ }^{6}$ Esta deve ser compreendida como proposição que trata de algo sem certezas.

${ }^{7}$ A noção de valor refere-se ao ato de admitir que um objeto, um ser ou um ideal exerça sobre a ação e as disposições à ação uma influência determinada.

${ }^{8}$ As hierarquias, tais como a superioridade dos homens sobre os animais, dos deuses sobre os homens, também servem de alicerce para a argumentação.

${ }^{9}$ No tratado, a noção de lugar, por um lado, está vinculada a uma metafísica particular e, do outro, à distinção dos tipos de objetos de acordos referentes ao real dos que se referem ao preferível. Assim, entende-se por lugares as premissas de ordem geral as quais Aristóteles estuda entre os lugares de acidentes.
} 


\section{$\mathrm{EI} \square \mathrm{\alpha A}$}

\subsection{Ethos em Maingueneau}

De acordo com Auchlin (2001, p. 93 apud Maingueneau 2011a, p. 12), "a noção de ethos é uma noção com interesse essencialmente prático, e não deve ser concebido como um conceito teórico claro [...]”. Pode-se inferir que, em nossa prática ordinária da fala, o ethos responde a questões empíricas efetivas, as quais têm como particularidade serem mais ou menos coextensivas ao nosso próprio ser. Ainda segundo este autor, para falar de ethos, é mister abordar, mesmo que brevemente, um pouco da Retórica antiga, uma vez que a primeira conceituação do termo "ethos" foi dada por Aristóteles.

Para Maingueneau (2011a), na Retórica aristotélica, havia uma preocupação em apresentar uma technè buscando examinar o que é persuasivo para tal ou qual tipo de indivíduo. Partindo desse ponto, pode-se afirmar que "a prova pelo ethos consiste em causar boa impressão pela forma como se constrói o discurso, a dar uma imagem de si capaz de convencer o auditório, ganhando sua confiança" (MAINGUENEAU, 2011a, p. 13).

É pensando nessa problemática que Maingueneau (2011a) vai afirmar que o ethos é resultado dos seguintes fatores: ethos pré-discursivo, ethos discursivo (ethos mostrado e dito). De acordo com o autor, também não se pode deixar de perceber que a diferença entre o ethos dito e mostrado se inscreve nos extremos de uma linha continua, pois não é possível definir uma fronteira explícita entre o puramente "mostrado" e o "dito" sugerido pela enunciação. Sendo assim, conclui-se que o ethos efetivo é produto da interação dessas diversas instâncias.

A Figura 1 ilustra bem a interação dessas diversas instâncias:

Figura 1 - A interação entre as diversas instâncias do ethos

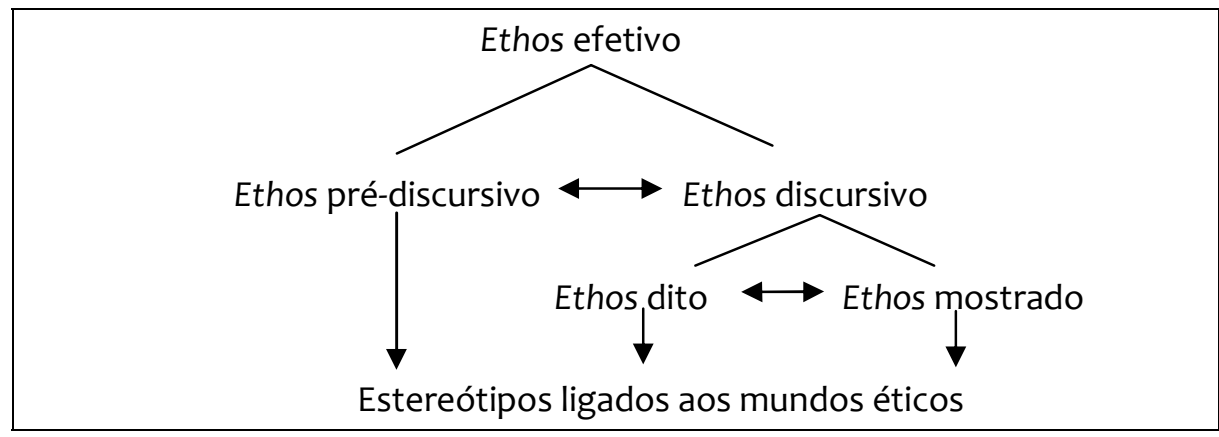

Fonte: Maingueneau (2011a, p. 19) 
Esta ilustração acerca do ethos efetivo possibilita tratar da noção de estereotipagem. Para Amossy (2011, p. 125-126), a estereotipagem deve ser compreendida como uma operação que consiste em pensar o real por meio de uma representação cultural preexistente, um esquema coletivo cristalizado. Por isso, ela afirma que a imagem que o orador constrói de si e a impressão que ele produz em seu auditório também são partes fundamentais para materialidade do ethos efetivo.

Para Maingueneau (2011b), todo discurso presume uma vocalidade específica, que permite relacioná-lo a uma fonte enunciativa, através de um tom que indica quem o disse. Aceitar essa noção de ethos não significa conceber o escrito como traço de uma oralidade primeira. A identidade de um posicionamento discursivo está vinculada a um tom específico que torna possível a vocalidade. Além disso, deve-se perceber que o "texto não é para ser contemplado, ele é enunciação voltada para um coenunciador que será necessário mobilizar para fazê-lo aderir 'fisicamente' a um certo universo de sentidos" (MAINGUENEAU, 2011b, p. 73). Isto o leva a defender a ideia de que "o discurso é um acontecimento inscrito em uma configuração sócio-histórica e não se deve dissociar a organização de seus conteúdos e o modo de legitimação de sua cena enunciativa" (MAINGUENEAU, 2011b, p. 74-75). Essa concepção é complexa, pois supõe um ethos marcado pela oposição entre o ethos oral/ethos escritural.

Ainda segundo Maingueneau (2011b, p. 75), qualquer discurso pressupõe uma cena de enunciação para se tornar enunciado. Na sua concepção, a "cena de enunciação" corresponde a três cenas, que ele classifica como "cena englobante", "cena genérica” e "cenografia”. A "cena englobante” deve ser entendida como o tipo de discurso - cabe a ela conferir ao discurso seu estatuto pragmático: literário, publicitário, filosófico, religioso, entre outros; A "cena genérica" corresponde ao contrato associado a um gênero, a uma "instituição discursiva": o sermão, o editorial, o guia turístico, entre outros; já a "cenografia” não é subalterna ao gênero, uma vez que ela é construída pelo próprio texto: um sermão poder ser enunciado por meio de uma cenografia professoral, profética, filosófica, etc. Na análise do corpus, esses pontos serão mais bem compreendidos. 


\section{Coronelismo}

Parafraseando Leal (1986), pode-se dizer que a cultura coronelista faz parte da história do Brasil, principalmente, nas cidades do interior. Segundo o autor, trata-se de um "fenômeno de imediata observação para quem procure conhecer a vida política no interior do Brasil é o malsinado "coronelismo"” (LEAL, 1986, p. 19). Afirma ainda que tal fenômeno não é simples, pois envolve um complexo de características da política municipal.

É Basílio de Magalhães - citado por Leal (1986) - quem apresenta a origem da palavra "coronelismo", esclarecendo que tal lexema foi incorporado em nossa língua com uma acepção particular, o que permite ser registrado como brasileirismo nos léxicos do lado de cá do Atlântico, por conta da remota origem do seu sentido translato aos autênticos ou falsos 'coronéis' da extinta Guarda Nacional ${ }^{10}$. O fato é que, além dos que realmente ocupavam na Guarda Nacional tal posto, o tratamento de 'coronel' passou a ser dado pelos sertanejos a todo e qualquer chefe político.

Conforme a concepção de Leal (1986), o coronelismo deve ser compreendido como um produto da superposição de formas desenvolvidas do regime representativo a uma estrutura econômica e social inadequada. Ele é, sobretudo, uma forma própria de manifestação do poder privado - uma adaptação calcada nos resíduos do nosso antigo poder privado que conseguem conviver com um regime político de extensa base representativa.

Nesse sentido, um aspecto que chama atenção é o da liderança, com a figura do coronel ocupando o lugar de maior destaque. Contudo, pode-se observar que nem sempre os chefes políticos municipais são realmente autênticos coronéis. Por conta da difusão do ensino superior no Brasil, iniciouse uma produção significativa, por todo o Brasil, de médicos e advogados cujos dons de comando os habilitavam à posição de chefia. Esses mesmos "doutores", quase sempre, são parentes ou pessoas próximas à família do "coronel".

Para Faoro (1997), se a riqueza é substancial à construção da pirâmide, não é fator necessário, uma vez que pode haver coronéis remediados, desprovidos de terras, embora seja impossível a corporificação no pobre ou no dependente, destituído de sua posição a arbítrio alheio. Em geral, o coronel

\footnotetext{
${ }^{10}$ Na perspectiva de Fertig (2010), a Guarda Nacional pode ser compreendida como milícia criada em 1831 pelo Império do Brasil e composta por todos os homens brasileiros que tivessem entre $21 \mathrm{e}$ 60 anos de idade e que pudessem votar nas eleições. Essa milícia serviu de alicerce políticoinstitucional na construção do Estado nacional brasileiro no século XIX.
} 
não manda porque tem dinheiro, mas porque lhe conferem esse poder em um pacto não escrito. Em suma, "o vínculo que lhe outorga poderes públicos virá, essencialmente, do aliciamento e do preparo das eleições, notando-se que o coronel se avigora com o sistema da ampla atividade dos cargos, por semântica e vazia que seja essa operação" (FAORO, 1997, p. 700).

Por conta desse retrato, os cidadãos que vivem no interior do Estado da Bahia, principalmente, os mais desprovidos de recursos, ainda se deparam com a figura do coronel nos dias atuais, uma vez que são muitas as dificuldades para sobreviver numa sociedade brasileira cuja estratificação social ratifica a hegemonia dos que têm mais prestígio, dinheiro e poder.

\title{
4. As marcas sócio-históricas do município de Esplanada
}

De acordo com os dados sócio-históricos de Esplanada, é correto afirmar que o marco inicial da cidade é a construção do trecho da estrada de ferro Bahia-São Francisco, interligando a cidade ao município de Alagoinhas. Segundo Faria (1998), os Engenheiros contaram com a ajuda do Coronel Euzébio Leal ${ }^{11}$ para construir um pequeno escritório na fazenda Cunhas, além de um atalho cujo objetivo era viabilizar a construção da linha férrea. Pouco tempo depois, já havia outro escritório próximo ao local onde ficariam os trilhos. Entre os diversos relatos, o autor afirma que

\begin{abstract}
[...] a casa grande da Baixinha, quase secular, ainda habitada, deve ser preservada e/ou tombada como um Monumento Histórico, que sempre foi um marco divisório das duas povoaç̃̃es. Quando surgiram as pseudo-guerrilhas, na ocasião em que o povo do Timbó se rebelou contra os trabalhadores da linha férrea, jamais houve contenda na área da baixinha, porque o Coronel Benício era muito respeitado e acalmava os ânimos, tanto que só depois os operários se aproximaram do comércio é que eram atacados violentamente (FARIA, 1998, p. 11).
\end{abstract}

A partir da citação supracitada, observa-se que os habitantes do Timbó tinham criado uma grande expectativa por conta da construção da linha férrea. Percebia-se quase um clima de festa, acreditando que Esplanada seria uma cidade melhor por causa desse acontecimento. Contudo, tudo acabou se transformando em uma ilusão. A cidade continua com problemas sócioeconômicos até hoje.

Outro ponto importante comentado pelo autor refere-se ao Frei José de Monsano, que, recém-chegado da Itália, instala-se no Convento dos

${ }^{11}$ O Coronel Euzébio Leal faz parte da história do munícipio de Esplanada, pois o mesmo já residia na localidade, quando o município ainda era um povoado. 
$\mathrm{EI} \square \mathrm{dA}$

Revista Eletrônica de Estudos Integrados em Discurso e Argumentação, Ilhéus, n. 17, jul./dez. 2018

Capuchinhos com o objetivo de recuperar sua saúde, a qual estava bem debilitada. Para Faria (1998), o Frei José de Monsano virou uma figura quase lendária da história de Esplanada. Conforme os relatos, ele foi preso injustamente no município de Entre Rios, por vingança de um Delegado de Polícia, devido a um comentário realizado na Missa. No dia do aniversário de Getúlio Vargas, o Frei foi denunciado ao Secretário de Segurança Pública, o qual mandou escoltá-lo - preso - para Salvador. Ainda segundo Faria (1998, p.46),

Esplanada se tornou o centro da Região por onde transitavam mercadorias de municípios vizinhos, por causa do meio de transporte ferroviário, que facilitou a remessa de tudo que vinha do nordeste, para a capital, quando, anteriormente, esta parte do Brasil vivia muito isolada, tornando-se, assim, mais atrasada e, até hoje, sente-se que a Região Sul foi mais beneficiada pelo progresso.

O autor também comenta a revolução constitucionalista de 1932, instaurada em São Paulo sob o comando do General Isidoro Dias Lopes. Por conta desse fato, vários policiais foram convocados para reforçar a guarda, fazendo com que muitos municípios ficassem sem policiamento, completamente desguarnecidos, dando oportunidade para o grupo de Lampião adentrar vários municípios do Estado da Bahia, como o município de Queimadas, onde foram assassinados quatro soldados - o Cabo Justino, que tinha família em Esplanada, foi uma das vítimas. Nesse período, a população ficara assustada com a notícia de que Lampião passaria por Inhambupe, Alagoinhas, Entre Rios, Esplanada, Cipó e Nova Olinda, até chegar à praia do Conde. Todavia, tudo não passou de um grande susto, uma vez que Lampião sumira, refugiando-se no Raso da Catarina.

Em 1994, Faria publica seu segundo livro: a autobiografia Oitenta anos de minha vida - Reminiscências. A partir dela, é possível conhecer fatos e relatos da história do município de Esplanada, assim como de outros municípios por onde ele passou.

Nesse livro, ele diz que, na mocidade, trabalhou como escrivão de casamento, participando de várias solenidades, convivendo, assim, com pessoas de "fino trato", não demorando muito para conquistar a confiança dos magistrados da época. Na sua visão, o povo em geral é muito fácil de ser enganado. Qualquer “milagreiro” consegue chamar a atenção do povo. Nesse sentido, comenta que:

[...] a carência do nosso povo é tanta, principalmente no que se refere a sobrevivência e no campo da saúde, que um pobre um não pode nem entrar no hospital e muito menos comprar um simples remédio para dor de cabeça, 
apelando muitas vezes para os políticos em troca de um voto, como se vê abertamente com tantos que aproveitam a época das eleições para atacarem os candidatos (FARIA, 1994, p. 49).

Através da citação supracitada, observa-se que a carência do povo não é de agora. As condições precárias das pessoas tornam-nas vulneráveis e reféns de si mesmas, principalmente, para os que residem em municípios pequenos, carentes de recursos e de empregos. Logo, não é difícil subverter os valores de boa parte dos eleitores, grande parte deles são pais e mães de família que tentam garantir o sustento de seus filhos. Todos sabem que votar no candidato que perdeu significa, muitas vezes, ter de sair da cidade, pois dificilmente iriam conseguir uma oportunidade de emprego na prefeitura.

\section{Análise do corpus}

Para tratar da educação, o candidato (R.C.L) começa abordando, primeiramente, os dados sócio-históricos objetivando fundamentar melhor o seu dizer. Observemos sua fala a seguir:

[...] a educação do nosso município é um celeiro de bons professores, de pessoas inteligentes; a cidade que sempre foi conhecida como a cidade dos doutores, apesar desse patrimônio pessoal que Esplanada tem, nós não temos vivido bons tempo na educação do nosso munícipio de Esplanada. Esplanada tem amargado os piores índices do Ideb da regiáo e um dos piores do estado. Esplanada vive com uma estrutura precária. (R.C.L., 2012).

No excerto, o candidato acaba ratificando, na memória dos eleitores, a ideia de que a cidade deve continuar sendo conhecida como a terra dos doutores, isto é, a terra dos "coronéis". De acordo com Leal (1986), o termo "Doutores" é uma das formas camufladas do antigo coronelismo, agora camuflado sob uma nova roupagem. Esse fragmento também nos possibilita pensar nas múltiplas questões ligadas ao campo político. $\mathrm{Na}$ visão de Charaudeau (2011), o campo político não pode ser desassociado da ação política, das instâncias e dos valores. Sendo assim, é possível inferir que esse enunciado nos possibilita refletir sobre as questões da ação política praticada pelo candidato R.C.L., das partes interessadas nessa ação e nos valores que nortearam o seu dizer.

No fragmento supracitado, identifica-se também que o candidato R.C.L. recorreu a um argumento quase-lógico, caracterizado como contradição. Conforme Perelman e Olbrechts-Tyteca (2005[1958]), este tipo de estratégia ocorre quando alguém defende uma proposição e sua negação ao mesmo 
tempo. O uso desse argumento fica evidenciado quando o candidato declara que a cidade é um celeiro de bons professores, de pessoas inteligentes, sendo conhecida como a cidade dos doutores. Mas também afirma que a cidade tem um dos piores índices do Ideb da região e um dos piores do Estado. Esta contradição ocorre em virtude de o candidato estar buscando utilizar argumentos que mobilizem as paixões de seu auditório.

Ao abordar os problemas ligados à educação, o candidato R.C.L. defende a ideia de que a infraestrutura do município não contribui para melhorar a qualidade do ensino. Por isso, ele sugere resolver o problema da seguinte forma:

[...] nós precisamos fazer da educação a mola mestra da revolução desse município, e isso passa por um projeto fundamental que é a educação de tempo integral (R.C.L.,2012).

Essa declaração passa uma imagem de que o candidato R.C.L. está atento às instancias de poder, pois sua proposta de governo parece sinalizar uma concordância com a meta do governo federal, que deseja implantar gradualmente uma educação de tempo integral em todas as escolas do Ensino Básico. Isso reforça a tese de Leal (1986), quando nos diz que sempre que possível, os prefeitos vão preferir estar na base aliada do governo do estado e do governo federal com o objetivo de conseguir mais recursos e programas para o município. Isso fica explícito no fragmento abaixo:

[...] veja, por exemplo, os programas de inclusão digital do governo federal, as escolas têm o computador, mas não tem o laboratório de informática montado, e nem quem use esses computadores (R.C.L.,2012).

Observa-se que o candidato R.C.L. constrói uma imagem de si, alicerçada no argumento do desperdício, pois ele comenta que os computadores não foram utilizados pelo grupo político do seu principal opositor. Na concepção de Perelman e Olbrechts-Tyteca (2005 [1958]), tal esquema argumentativo, que se baseia na estrutura do real, defende a ideia de que, uma vez iniciado um trabalho, deve-se prosseguir na mesma direção. Assim, depreende-se que o candidato R.C.L. também está atento aos interesses e às paixões dos alunos que desejam o laboratório de informática.

Antes de prosseguir, é necessário sinalizar que o termo "nós" aparece várias vezes no discurso do candidato R.C.L., o qual gera um duplo sentido uma aproximação com o eleitor e, ao mesmo tempo, um deslocamento do peso de sua responsabilidade como futuro gestor do poder executivo. Por 
meio do seu dizer, ele constrói uma cena de enunciação em que demonstra estar comprometido com a educação. Por isso, explicita que, antes mesmo de ser eleito, já estava tentando garantir a implantação do IFBA, no município de Esplanada. Eis a sua fala:

[...] nós estamos tentando trazer para Esplanada, o que já é um compromisso da reitora Aurina Santana - o IFBA para o município de Esplanada, ou seja, será a oportunidade dos nossos jovens ao concluírem o ensino médio - já terem uma profissão (R.C.L., 2012)

A fala supracitada é muito interessante, pois vincula a educação ao mercado de trabalho. Assim, ele cria nos eleitores a expectativa de que Esplanada terá uma instituição cujo ensino é sinônimo de qualidade e, ao mesmo tempo, a ideia de que a implantação IFBA irá aumentar a oferta de emprego em diversos setores.

Na tentativa de harmonizar a construção do ethos dito e o mostrado, ele recorre a um argumento de autoridade. Observemos:

[...] digo isso com a autoridade de quem tem um dos melhores professores do Brasil, que é o secretário municipal de educação de Salvador - Deputado João Carlos Bacelar (R.C.L., 2012).

A argumentação acima é utilizada, principalmente, em virtude do Deputado João Carlos Barcelar pertencer ao mesmo partido político - PTN. Para Perelman e Olbrechts-Tyteca (2005), é muito comum que o orador, na tentativa de concretizar o interesse de sua argumentação, busque situar o debate no plano que Ihe for mais favorável, alterando, caso seja preciso, o estatuto de certos acordos. Sendo assim, Maingueneau (2011a) está certo ao afirmar que ethos efetivo é produto da interação dessas diversas instâncias. As cenas de enunciação parecem cumprir um papel fundamental nesse jogo.

Para tratar da segurança pública, o candidato R.C.L. tece um comentário que nos possibilita refletir acerca da problemática da diferença entre o ethos dito e mostrado, pois ela se inscreve nos extremos de uma linha continua, não sendo possível delimitar uma fronteira explícita entre o puramente "mostrado" e o "dito" sugerido pela enunciação, conforme explicita Maingueneau (2011a). Observemos o fragmento abaixo:

[...] alguns governantes têm a mentalidade pequena de atribuir ao governo do estado ou governo federal. É bem verdade que constitucionalmente essa é uma responsabilidade dos Estados e da União (R.C.L., 2012). 
O fragmento supracitado nos possibilita inferir que, apesar de o candidato R.C.L. não especificar quais são os governantes que ele está desqualificando, os eleitores do município de Esplanada sabem que ele está se referindo às gestões do candidato J.A.C, pois este governou por dois mandatos e ainda conseguiu eleger o seu sucessor D.B na eleição de 2008.

$\mathrm{Na}$ visão do candidato R.C.L., a segurança pública é uma responsabilidade do governo do estado e do governo federal. Para defender a sua tese, argumenta dizendo que

[...] a própria União, como fez com a educação, que foi municipalizada, como fez com a saúde, que foi municipalizada, também tem criado, tem reconhecido a sua incapacidade de dar assistência igual aos municípios brasileiros e tem criado mecanismos federais para financiar uma segurança municipal (R.C.L., 2012).

Esse argumento serve para sugerir que ele tem conhecimento sobre o que está falando, aumentando, assim, a credibilidade da imagem do orador. Isso fica mais evidente no fragmento abaixo:

[...] eu, particularmente, sou IDEALIZADOR e presidente da comissão da Câmara Municipal da Segurança Pública. Trouxe pra esse município a comissão de direitos humanos e segurança pública da assembleia legislativa para discutir segurança pública (R.C.L., 2012).

Ao dar um tom enfático ao termo "idealizador", o candidato R.C.L. produz enunciado cujo efeito de sentido materializa um ethos político que realiza ações ligadas à Segurança Pública desde outrora. Isso reforça a ideia de que ele, visando obter os votos dos eleitores, elabora sua fala ancorada nos estereótipos culturais da cidade, tentando garantir uma aproximação com seus coenunciadores, pois quase todos os eleitores sabem que a cidade de Esplanada carece de Segurança Pública, desde sua fundação.

Observando o contexto sócio-histórico da cidade, por exemplo, verificase que Faria (1998) trata da falta de segurança pública, quando comenta o período que surgiram as pseudo-guerrilhas, momento em que os moradores do Timbó se rebelaram contra os trabalhadores da linha férrea, explicitando que, por conta da intervenção do Coronel Benício, foi possível sanar a violência em certa medida.

O candidato R.C.L. é um nativo de Esplanada. Logo, ele sabe que o problema da Segurança Pública não é de agora, assim como tem conhecimento de que a resolução do problema não é simples. No entanto, 
$\mathrm{EI} \sqcap \mathrm{dA}$

Revista Eletrônica de Estudos Integrados em Discurso e Argumentação, Ilhéus, n. 17, jul./dez. 2018

com o objetivo de conquistar o voto dos eleitores, faz uso do seguinte argumento:

[...] nós podemos melhorar nossa segurança pública CRIANDO de verdade nossa Guarda Municipal, fazendo com que ela se capacite através de um treinamento específico. Aqui nós temos um centro de treinamento que está ali, no litoral norte, ou seja, os policiais do Estado, das guarnições especializadas, são treinados em Esplanada, e porque é que essa estrutura não pode servir para treinar nossa guarda municipal? Eu visitei o município de Novo Hamburgo, de Campo Bom, no Rio Grande do Sul, um município que tem duzentos e cinquenta mil habitantes e outro que tem trinta mil habitantes, e pude ver guardas municipais que funcionam, que fazem blitz, que auxiliam as polícias Civil e Militar, que cuidam do trânsito, que cuidam do patrimônio público e que ajudam efetivamente a resolver os problemas de segurança pública daquelas cidades (R.C.L., 2012).

Nesse trecho, o candidato R.C.L. busca dar um tom enfático ao enunciado - "nós podemos melhorar nossa segurança pública CRIANDO de verdade nossa Guarda Municipal" - objetivando sinalizar que, caso seja eleito, não dará continuidade à cultura do desvio de função do cargo de Guarda Municipal. Com essa fala, o candidato R.C.L visa a conquistar uma parte dos eleitores, já que muitos deles se sentem desvalorizados por não exercer sua função segundo o que foi especificado no edital do concurso. Trata-se de uma característica típica não apenas da cidade de Esplanada, mas de boa parte das prefeituras das cidades do interior - interpretada por muitos como desvio de função. O desvio de função também é visto como uma prática da cultura coronelista, uma vez que os prefeitos podem recorrer a essa prática como forma de troca de favor e/ou como forma de "compra de voto". Por isso, o candidato R.C.L. segue desqualificando as gestões passadas e, paralelamente, ele tenta criar um ethos de um político virtuoso, de um político não coronelista. Essa cena nos faz pensar na estereotipagem que cada candidato tem um do outro, pois, como explicita Amossy (2011), a estereotipagem deve ser compreendida como uma operação que consiste em pensar o real por meio de uma representação cultural preexistente, um esquema coletivo cristalizado.

Nesse sentido, pode-se dizer que o candidato constrói ethos para dizer eu sou isto (político honesto, revolucionário, portanto, não coronelista) e um anti-ethos para dizer - eu não sou isto (político despreparado, patriarcal, personalista, logo, coronelista). 


\section{$\mathrm{EI} D \bar{\alpha} \mathrm{A}$}

\section{Considerações finais}

A partir da perspectiva de Análise do Discurso desenvolvida por Maingueneau, buscou-se observar, na entrevista do candidato eleito a prefeito de Esplanada (BA), durante o processo eleitoral de 2012, os possíveis traços do ethos coronelista. Para isso, refletiu-se, primeiro, sobre a noção de discurso político apresentada por Charaudeau, pois este defende a tese de o discurso político ser concebido como um jogo de máscaras. Já a noção de argumentação defendida por Perelman e Olbrechts-Tyteca possibilitou inferir que as estratégias discursivas foram abordadas a partir do reconhecimento de técnicas argumentativas mobilizada pelo orador, no desenvolvimento dos temas abordados. A ideia de Maingueneau acerca da noção de ethos associado às cenas de enunciação foi adequada para compreender a materialidade do ethos coronelista em Esplanada. Isso ratifica a tese de Leal, quando infere que fenômeno da vida política no interior do Brasil é marcado por um desvirtuado "coronelismo" .Por fim, pode-se dizer que, como o corpus foi o discurso político, a cena englobante é o discurso político, a cena genérica é a entrevista realizada pelo Esplanada News, e as cenografias alternam - ora é de um administrador, ora é de um político revolucionário. Esta estratégia possibilitou construir um ethos para dizer - eu sou isto (político honesto, revolucionário, comprometido em não agir como um coronelista) e um antiethos - eu não sou isto (político despreparado, patriarcal, personalista).

\section{Fontes}

ENTREVISTA COM RODRIGO DE DEDÉ. Direção: Portal Esplanada News. Esplanada (BA), 27:24 minutos. Disponível em: https://www.youtube.com/watch?v=gO6sNoy2Z2U. Acesso em: 1 nov.2012.

\section{Referências}

AMOSSY, Ruth. Imagens de si no discurso: a construção do ethos. 2. ed. Tradução: Dilson Ferreira da Cruz et al. São Paulo: Contexto, 2011.

ARENDT, Hannah. Condition de l'homme modern. Paris: Calmann-Levy, 1961.

AUCHLIN, Antoine. Ethos et expérience du discours: quelques remarques. In: WAUTHION, Michel; SIMON, Anne Catherine (org.). Politesse et idéologie. 
$\mathrm{EI} \square \bar{\alpha} \mathrm{A}$

Revista Eletrônica de Estudos Integrados em Discurso e Argumentação, Ilhéus, n. 17, jul./dez. 2018.

Rencontres de pragmatique et de rhétorique conversationelle. Louvain: Peeters, 2001. p. 77-95.

CHARAUDEAU, Patrick. O discurso político. Tradução: Fabiana Komesu e Dilson Ferreira da Cruz. 2. ed. São Paulo: Contexto, 2011.

CHARAUDEAU, Patrick; MAINGUENEAU, Dominique. Dicionário de Análise do Discurso. Coordenação da tradução: Fabiana Komesu. 3. ed. São Paulo: Contexto, 2012.

FAORO, Raymundo. Os donos do poder: formação do patronato político brasileiro. 12 . ed. São Paulo: Globo, 1997. v. 12.

FARIA, Hildeth Cardoso. História de Esplanada, desde o seu início, no final do século XIX. Salvador: Art-Contemp, 1998.

FARIA, Hildeth Cardoso. Oitenta anos de vida - Reminiscências. Salvador: ArtContemp, 1994.

FERTIG, André Atila. Valentes vingadores: os guardas nacionais rio-grandenses como símbolos do Império do Brasil. Revista Escritas, Goiânia, v. 2, p. 123-146, 2010. Disponível em: https://sistemas.uft.edu.br/periodicos/index.php/escritas/article/view/1146/8040. Acesso em: 7 ago.2016.

LEAL, Victor Nunes. Coronelismo, Enxada e voto: o município e o regime representativo, no Brasil por Victor Nunes Leal. Notas: Basílio de Magalhães. Prefácio: Barbosa Lima Sobrinho. 2. ed. São Paulo: Alfa-Ômega, 1986.

MAINGUENEAU, Dominique. A Propósito do ethos. Tradução: Luciana Salgado. In: MOTA, Ana Raquel; SALGADO, Luciana (org.). Ethos discursivo. 2. ed. São Paulo. Contexto, 2011 a. p. 11-32.

MAINGUENEAU, Dominique. Ethos, cenografia, incorporação. Tradução: Sírio Possenti. In: AMOSSY, Ruth (org.). Imagens de si no discurso: a construção do ethos. 2. ed. São Paulo, Contexto, 2011b. p. 69-92.

PERELMAN, Chaïm; OLBRECHTS-TYTECA, Lucie. Tratado da argumentação: a nova retórica. Tradução: Maria Ermantina de Almeida Prado Galvão. 2. ed. São Paulo: Martins Fontes, 2005 [1958].

POINCARÉ, Henri. La valeur de la science. Genebra: Editions du Cheval Ailé, 1946.

Forma de citação sugerida

SILVA, Elias Ramos da. Discurso político e o ethos coronelista em Esplanada, Bahia. EID\&A - Revista Eletrônica de Estudos Integrados em Discurso e Argumentação, Ilhéus, n. 17, p. 51-68, jul./dez.2018. DOI dx.doi.org/10.17648/eidea-17-1954. 